\title{
SOME NOTES ON GREEN-OSHER'S INEQUALITY
}

\section{Laiyuan Gao, Shengliang Pan and Yunlong Yang}

\begin{abstract}
In this note we will first focus our attention on the equality case of Green-Osher's inequality and show that its equality holds if and only if the curve $\gamma$ is a circle under the assumption that the function $F(x)$ is strictly convex on $(0,+\infty)$. As applications of Green-Osher's inequality we will then give some new geometric inequalities about convex plane curves. Finally, we will derive an upper bound estimate of Green-Osher's difference via the method of deforming convex curves into finite circles.
\end{abstract}

Mathematics subject classification (2010): 52A38, 52A40, 53A04.

Keywords and phrases: Green-Osher's inequality, geometric inequalities, Green-Osher's difference.

\section{REFERENCES}

[1] T. Bonnesen \& W. Fenchel, Theory of Convex Bodies, BCS Associates, Moscow, ID, 1987.

[2] Yu. D. Burago \& V. A. Zelgaller, Geometric Inequalities, Springer-Vertag, Berlin, 1988.

[3] K. S. Chou \& X. P. Zhu, The Curve Shortening Problem, CRC Press, Boca Raton, FL, 2001.

[4] Y. DAI, W. X. XU \& J. ZHou, Some Bonnesen style inequalities and planar isoperimetric deficit upper limit, Proceedings of The Fourteenth International Workshop on Diff. Geom., 14 (2010), 69-76.

[5] F. EdLeR, Vervollständigung der Steinerschen elementargeometrischen Beweise für den Satz, das der Kreis grösseren Flächeninhalt besitzt als jede andere ebene Figur gleich grossen Umfangs, Nachr. Ges. Wiss. Göttingen, 1882, 73-80. [Translated into French and printed in Bull. Sci. Math. 7, 2 (1883), 198-204].

[6] M. E. GAGE, An isoperimetric inequality with applications to curve shorting, Duke Math. J. 50 (1983), $1225-1229$.

[7] M. E. Gage, Curve shortening makes convex curves circular, Invent. Math. 76 (1984), 357-364.

[8] M. E. GAGE, On an area-preserving evolution equation for plane curves, in Nonlinear Problems in Geometry (D. M. DeTurck edited), Contemp. Math. 51 (1986), 51-62.

[9] M. E. Gage \& R. S. Hamilton, The heat equation shrinking convex plane curves, J. Diff. Geom. 23 (1986), 69-96.

[10] M. GREEN \& S. OsHER, Steiner polynomials, Wulff flows, and some new isoperimetric inequalities for convex plane curves, Asian J. Math. 3 (1999), 659-679.

[11] L. S. JiAng \& S. L. PAN, On a non-local curve evolution problem in the plane, Communications in analysis and geometry 16 (2008), 1-26.

[12] G. LAWLOR, A new area maximization proof for the circle, Mathematical Intelligencer 20 (1999), $29-31$.

[13] P. LAX, A short path to the shortest path, Amer. Math. Monthly 102 (1995), 158-159.

[14] D. S. Mitrinović, J. E. Peč ARIć \& V. Volenec, Recent Advances in Geometric Inequalities, Kluwer Academic Publishers, Boston, 1989.

[15] S. Montiel \& A. Ros, Curves and Surfaces, American Mathematical Society, Real Sociedad Matemática Española (RSME), 2005.

[16] R. Osserman, Curvature in the Eighties, Amer. Math. Monthly 97 (1990), 731-736.

[17] K. Ou \& S. L. PAN, Some remarks about closed convex curves, Pacific J. Math. 248, 2 (2010), $393-$ 401.

[18] S. L. PAN \& J. N. YANG, On a non-local perimeter-preserving curve evolution problem for plane convex curves, Manuscripta Math. 127 (2008), 469-484. 
[19] A. Ros, Compact hypersurfaces with constant scalar curvature and a congruence theorem, J. Diffenential Geom. 27 (1988), 215-220.

[20] R. SchneIder, Convex Bodies: the Brunn-Minkowski Theory, Cambridge University Press, Cambridge-New York, 1993.

[21] J. STEINER, Sur le maximum et le minimum des figures dans le plan, sur la sphere, et dans l'espace en général, I and II, J. Reine Angew. Math. (Crelle) 24 (1842), 93-152 and 189-250.

[22] G. Talenti, The standard isoperimetric inequality, in: Handbook of Convex Geometry, Vol. A (edited by P. M. Gruber and J. M. Wills), 73-123, Amsterdam: North-Halland, 1993.

[23] J. Zhou, Curvature inequalities for curves, Inter. J. Comp. Math. Sci. Appl. 1 (2007), 145-147. 